\title{
Adrenergic Control of Circulating Lymphocyte Subpopulations Effects of Congestive Heart Failure, Dynamic Exercise, and Terbutaline Treatment
}

Alan S. Maisel, Kirk U. Knowlton, Patrick Fowler, Ann Rearden, Michael G. Ziegler, Harvey J. Motulsky, Paul A. Insel, and Martin C. Michel

Departments of Medicine, Pharmacology, and Pathology, University of California San Diego, San Diego,

California 92037; and Veterans Administration Medical Center, San Diego, California 92161

\begin{abstract}
The current studies were undertaken to explore the relationship between enhanced sympathetic nervous activity and lymphocyte subset distribution in three settings: congestive heart failure, dynamic exercise, and $\beta$-adrenergic agonist treatment. We compared the number and subset distribution of circulating lymphocytes in 36 patients with congestive heart failure and 31 age-matched control subjects. The number of circulating lymphocytes was lower in heart failure than in control. This was due to a reduction in $\mathbf{T}_{\text {suppressor/cytotoxic }}$ and natural killer cells without significant alteration of $T_{\text {helper }}$ cells. The extent of the alteration was similar in patients with idiopathic and ischemic heart failure, but the reduction was more pronounced in patients with New York Heart Association class III-IV than in class I-II. The plasma catecholamine elevation in heart failure was also independent of etiology but more pronounced in the more severely ill patients. We also assessed lymphocyte subsets after acute stimulation of sympathetic activity by dynamic exercise and after treatment with the $\beta$-adrenergic agonist terbutaline. Dynamic exercise until exhaustion increased the number of circulating lymphocytes in healthy controls and heart failure patients in a subset-selective manner. By contrast, a 7-d treatment with terbutaline caused a reduction in the circulating number of lymphocytes in some subsets that was identical to that seen in heart failure patients. We conclude that prolonged sympathetic activity reduces the number of circulating lymphocytes by a $\beta$-adrenergic mechanism. Such alterations might be involved in the pathophysiology of heart failure and other disease states involving increased activity of the sympathetic nervous system. (J. Clin. Invest. 1990. 85:462-467.) beta receptors - lymphocytes - heart failure • sympathetic nervous system
\end{abstract}

\section{Introduction}

A heightened activity of the sympathetic nervous system plays an important role in the pathophysiology of various disease states. This can have beneficial effects under some circumstances, e.g., in congestive heart failure $(\mathrm{CHF}){ }^{1}$ where it ap-

Address reprint requests to Dr. A. S. Maisel, Cardiology Section (111A), Veterans Administration Medical Center, 3350 La Jolla Village Drive, San Diego, CA 92161.

Received for publication 4 November 1988 and in revised form 15 September 1989

1. Abbreviations used in this paper: $\mathrm{CHF}$, congestive heart failure; NK, natural killer cell; $\mathrm{T}_{\mathrm{h}}, \mathrm{T}_{\text {helper }}$ cell; $\mathrm{T}_{\mathrm{s} / \mathrm{c}}, \mathrm{T}_{\text {suppressor/cytotoxic }}$ cell.

The Journal of Clinical Investigation, Inc.

Volume 85, February 1990, 462-467 pears to help maintain perfusion pressure in the face of a decreased effective plasma volume (1). On the other hand, prolonged elevation of sympathetic activity can have adverse effects, e.g., in hypertension (2), in hemodialysis-induced hypotension (3), or in settings such as pheochromocytoma, in which circulating catecholamine levels are extremely high (4).

Growing evidence suggests that immune function is regulated in part by the sympathetic nervous system (for review, 5). We therefore speculated that the chronically increased sympathetic activity in disease states like CHF might affect the immune system. Accordingly, we determined the number and subset composition of circulating leukocytes in patients with CHF compared to healthy controls. We performed additional experiments in which acute increases in sympathetic activity were produced by dynamic exercise, or in which healthy subjects were treated with the $\beta_{2}$-adrenergic agonist terbutaline. Our results demonstrate that chronic $\beta$-adrenergic receptor stimulation by endogenous or exogenous catecholamines decreases the number of circulating lymphocytes in a subset-selective manner. Acute stimulation of sympathetic activity appears to have opposite effects.

\section{Methods}

The following study protocol was approved by the University of California San Diego Committee for investigations involving human subjects. Informed consent was obtained from each subject.

Heart failure patients. We studied 36 patients from the San Diego Veterans Administration Medical Center (age range 35-75 yr, mean \pm SEM: $58 \pm 2$ ) with stable CHF New York Heart Association (NYHA) class I-IV. None of them showed signs of viral or bacterial infections. Each patient had a clinical history of CHF for at least 6 mo; 4 patients were in class IV, 12 in class III, 17 in class II, and 3 in class I. The latter three patients had had more severe heart disease, but were now classified as I after treatment with vasodilators. 17 patients were known to have occlusive coronary artery disease (CAD) as documented either by coronary arteriography or a well documented myocardial infarction, 5 patients had presumed alcoholic cardiomyopathy, and 14 were classified as idiopathic. The ischemic cardiomyopathy patients were either "burnt out CAD" patients or had undergone angioplasty or bypass surgery after large anterior wall myocardial infarctions. Left ventricular ejection fraction, determined by equilibriumgated radionuclide ventriculography, averaged $30 \pm 2 \%$. All patients were receiving digitalis and diuretics, and most were on long-term therapy with vasodilator drugs ( 21 with nitrates, 9 with hydralazine, and 27 with angiotensin-converting enzyme inhibitors). Patients had not received adrenergic agonists or antagonists for at least $3 \mathrm{wk}$ before study. All cardiac medications were withdrawn for 12-24 $\mathrm{h}$ before study.

These CHF patients were compared with 31 healthy control subjects (age range 26-91 yr, mean \pm SEM: $60 \pm 4$ ) with no history of cardiac impairment.

Exercise treadmill testing. A subgroup of control subjects and $\mathrm{CHF}$ patients (NYHA class I-III) were exercised to exhaustion on a tread- 
mill using either the Bruce or Balke-Ware protocol. A venous blood sample was obtained before and on completion of the exercise. 12 electrocardiographic leads were recorded during and for $6 \mathrm{~min}$ after the conclusion of the exercise test, and there were no ST segment changes or evidence of treadmill-induced angina in any patient or control subject. Six of the patients with ischemic cardiomyopathy had underlying conduction system disorders that precluded ST segment analysis. A mercury sphygmomanometer and stethoscope were used at 3-min intervals during and after exercise to measure arterial blood pressure. The double product (product of systolic blood pressure and heart rate) was calculated for each patient as a measurement of cardiac output.

Protocol of study with terbutaline administration. We studied 12 healthy, drug-free men aged 24-43 yr with no history of diabetes, hypertension, or cardiac or thyroid disease. None of them showed signs of viral or bacterial infections. After the first blood withdrawal, the volunteers were given $5 \mathrm{mg}$ terbutaline three times daily for $7 \mathrm{~d}$. All subjects noted increased tremulousness during the first 24-36 $\mathrm{h}$ after drug intake, but this abated and all subjects were able to complete the study. On the morning of day 8 ( $12 \mathrm{~h}$ after the last terbutaline dose), blood was withdrawn again.

Mononuclear cell isolation. Blood $(120 \mathrm{ml})$ was routinely withdrawn between 8-10 a.m. after a 20-min resting period in the supine (heart failure study) or sitting position (terbutaline study). The subgroup of patients, who were either exercised or who had catecholamine determinations, reported in a fasting state to the exercise laboratory where an in-dwelling catheter was placed in a forearm vein. They then lay supine in a quiet room for $20 \mathrm{~min}$, and a venous blood sample was drawn.

Blood was placed in tubes containing EDTA ( $5 \mathrm{mM}$ final) and an equal volume of PBS solution was added. Mononuclear leukocytes were isolated and washed according to previously published techniques $(6,7)$. More than $90 \%$ of these cells were viable as assessed by trypan blue exclusion. A separate tube of blood (with EDTA) was used for automated white blood cell and differential count.

Plasma catecholamines were determined radioenzymatically using published techniques (8)

Flow cytometric analysis of mononuclear leukocyte. Lymphocyte subsets were detected by specific mouse monoclonal antibodies (obtained from Becton Dickinson Immunocytometry Systems, Mountain View, CA) that were conjugated directly with either FITC or phycoerythrin. Antibodies used for the identification of lymphocyte subsets are listed in Table $I$.

$20 \mu \mathrm{l}$ of monoclonal antibody reagent was reacted with $50 \mu \mathrm{l}$ of mononuclear cells $\left(10^{6}\right.$ cells) in $12 \times 75-\mathrm{mm}$ tubes for $30 \mathrm{~min}$ in an ice-cold water bath. Cells were washed twice with PBS supplemented with $0.1 \%$ sodium azide, and finally resuspended in $1 \mathrm{ml}$ of PBS supplemented with $0.05 \%$ paraformaldehyde. Cells were stored at $2-8^{\circ} \mathrm{C}$ until analyzed.

Immunofluorescence was measured with a flow cytometer (FACScan; Becton Dickinson Immunocytometry Systems) equipped with a 15-mW argon-ion laser and interfaced with a model 310 computer (Hewlett-Packard Co., Palo Alto, CA). Data analysis was performed

Table I. Monoclonal Antibodies Used for the Identification of Lymphocyte Subsets

\begin{tabular}{|c|c|c|c|}
\hline Cluster & Antibody & Isotype & Distribution \\
\hline CD3 & Anti-Leu 4 & IgGIk & Mature T lymphocytes \\
\hline CD4 & Anti-Leu 3a & IgGIk & Helper, inducer T lymphocytes \\
\hline CD8 & Anti-Leu 2a & IgGIk & Suppressor/cytotoxic lymphocytes \\
\hline CD19 & Anti-Leu 12 & IgGIk & B lymphocytes \\
\hline CD16 & Anti-Leu 11a & IgGIk & $\begin{array}{l}\text { Fc IgG receptor on NK cells and } \\
\text { neutrophils }\end{array}$ \\
\hline- & Anti-Leu 7 & IgMk & T lymphocyte and NK subsets \\
\hline- & Anti-Leu 19 & IgGIk & NK cells, cytotoxic $\mathrm{T}$ cell subsets \\
\hline
\end{tabular}

using the Consort 30 Data Management program supplied by the manufacturer. 5,000 cells were analyzed per sample. Electronic "gating" of the lymphocyte population was performed based on forward and side-scatter parameters. Percent-positive fluorescence of the gated population was determined relative to the fluorescence of the negative control cells. The relative proportion of each subset was obtained as a percentage of the total lymphocytes counted, and the absolute number in each subset was calculated by multiplying the percentage of each subset with the absolute lymphocyte count derived from the white blood cells and differential count.

Data analysis. Data shown are means \pm SEM of $n$ experiments. The significance of differences between groups was assessed by two-tailed paired (exercise and terbutaline study) and unpaired (heart failure study) $t$ tests without correction for multiple comparisons.

\section{Results}

Lymphocyte subsets in heart failure patients. The number of circulating lymphocytes, but not that of total white blood cells, was decreased in patients with CHF (Table II). This reduction was not randomly distributed, and affected only some lymphocyte subsets. The number of circulating B cells was not assessed in this part of our study. The number of circulating natural killer (NK) cells was decreased as assessed by three different monoclonal antibodies (Fig. 1). The number of cells positive for Leu 7/2, a lymphocyte subset believed to be associated with antiviral activity (9), was especially low in CHF patients $(150 \pm 26$ vs. $317 \pm 37$ cells $/ \mu 1, P<0.002)$.

The number of circulating $T$ cells was also decreased in CHF patients (Fig. 1). Among the T cells, however, the reduction was again found in only some subsets. The number of $\mathrm{T}_{\text {suppressor/cytotoxic }}\left(\mathrm{T}_{\mathrm{s} / \mathrm{c}}\right)$ cells was decreased by $\sim 50 \%$, whereas that of $T_{\text {helper }}\left(T_{h}\right)$ cells was not significantly altered. Thus, $T_{h}$ cells accounted for a higher percentage of $\mathrm{T}$ cells in CHF patients $(44.4 \pm 1.8$ vs. $35.4 \pm 1.7 \%, P=0.0006)$, and the calculated ratio $T_{h} / T_{s / c}$ cells was greater in CHF patients $(2.3 \pm 0.2)$ than in control subjects $(1.2 \pm 0.1, P<0.0001)$.

To further characterize the alteration of circulating lymphocytes in CHF, we separated patients according to the etiology and severity of their disease. Patients whose CHF was due to ischemic heart disease $(n=17)$ had similar cell numbers of each lymphocyte subset as did patients with idiopathic $\mathrm{CHF}$ (Fig. $2 A$ ). However, when classified according to severity, patients .with NYHA class III-IV had a more pronounced decrease of $T_{s / c}$ and NK cells than did patients with NYHA class I-II (Fig. 2 B). Similarly, plasma catecholamine levels (measured in 19 patients) were substantially higher in patients with more severe heart failure but did not differ between ischemic or idiopathic CHF (Fig. 2, insets). These differences can not be explained by different treatment modalities, since both groups

Table II. Comparison of White Blood Cell and Lymphocyte Count in Heart Failure Patients and Control Subjects

\begin{tabular}{lccr}
\hline & Control subjects & Heart failure patients & \multicolumn{1}{c}{$P$ value } \\
\hline White blood cells & $7107 \pm 494$ & $8534 \pm 531$ & 0.0055 \\
Lymphocyte number & $1953 \pm 118$ & $1447 \pm 100$ & 0.0016 \\
\% Lymphocytes & $29.1 \pm 1.5$ & $18.1 \pm 1.4$ & $<0.0001$
\end{tabular}

All numbers are mean \pm SEM of 31 (control subjects) and 36 (heart failure patients). Cell numbers are given as cell $/ \mu \mathrm{l}$. 


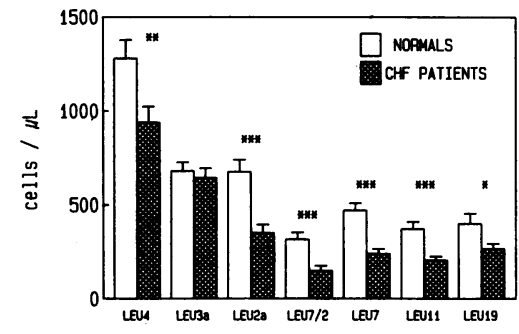

Figure 1. Subsets of circulating lymphocytes in control subjects and patients with heart failure. Shown are total $\mathrm{T}$ cells $\left(\right.$ Leu $\left.4^{+}\right), T_{h}$ cells $($ Leu $\left.3 \mathrm{a}^{+}\right), \mathrm{T}_{\mathrm{s} / \mathrm{c}}$ cells (Leu $\left.2 a^{+}\right)$, the Leu $7 / 2^{+}$subset, and NK cells (Leu $7,+$ Leu $19,+$ and Leu

$\left.11^{+}\right)$. Data are presented as means \pm SEM of the number of cells $/ \mu \mathrm{l}$ blood from 31 control subjects and 36 heart failure patients. ${ }^{*} P<$ $0.05,{ }^{* *} P<0.01,{ }^{* * *} P<0.001$ vs. control subjects by unpaired twotailed $t$ test.

were on similar drug regimens. Taken together, these data prompted us to investigate the effect of catecholamines on circulating lymphocytes in more detail.

Lymphocyte subsets after acute stimulation of sympathetic activity. In order to investigate the effects of acute stimulation of sympathetic activity on circulating lymphocytes, we exercised a subset of healthy controls $(n=16)$ and a group of patients with CHF ( $n=14$, NYHA class I-III only) on a treadmill until exhaustion. Patients with severe heart failure (NYHA class IV) did not participate in this part of the study. As expected, patients with $\mathrm{CHF}$ demonstrated considerably less exercise tolerance than did control subjects (double product: $18,100 \pm 800$ vs. $26,600 \pm 2,700, P<0.001$ ). The exercise test increased plasma norepinephrine and epinephrine levels somewhat less in CHF patients than in control subjects (Table III).

In control subjects, dynamic exercise increased the number of circulating white blood cells and lymphocytes, but the increase was unevenly distributed among lymphocyte subsets.

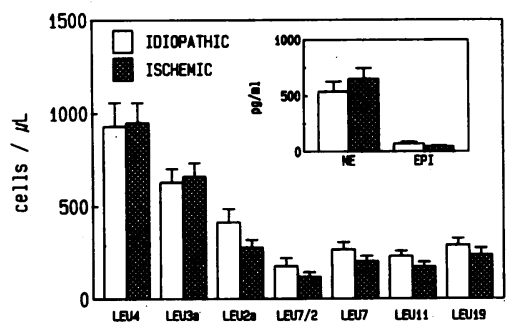

B

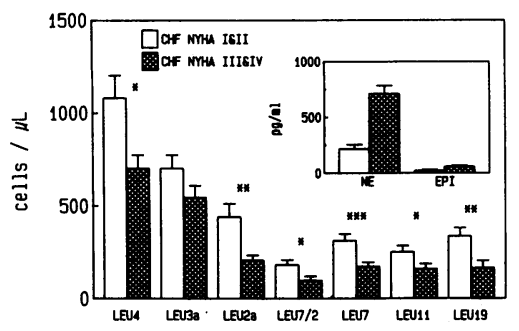

Figure 2. Subsets of circulating lymphocytes in patients with $(a)$ ischemic and idiopathic heart failure (up), and (b) with less (NYHA class I-II) and more severe (NYHA class IIIIV) heart failure. Shown are total $T$ cells (Leu $\left.4^{+}\right), T_{h}$ cells $\left(\right.$ Leu $\left.3 a^{+}\right)$, $T_{s / c}$ cells $\left(\right.$ Leu $\left.2 a^{+}\right)$, the Leu $7 / 2^{+}$subset, and NK cells $\left(\right.$ Leu $7,{ }^{+}$Leu $19,{ }^{+}$and Leu $11^{+}$). Data are presented as means \pm SEM of the number of cells $/ \mu \mathrm{l}$ blood from 17 patients with ischemic and 19 with idiopathic heart failure, and 13 patients with class I-II and 11 with class III-IV (12 patients were classified as class I-III and not included in this analysis). Insets show mean \pm SEM of plasma norepinephrine (NE) and epinephrine (EPI) levels in $\mathrm{pg} / \mathrm{ml}$. Significance of differences was assessed by unpaired two-tailed $t$ test.
The number of circulating $T_{\mathrm{s} / \mathrm{c}}$ and NK cells increased by more than $100 \%$ during dynamic exercise (Fig. $3 \mathrm{~A}$ ). In contrast, the number of $T_{h}$ cells did not significantly change. Patients with CHF showed qualitatively similar changes after exercise (Fig. 3 $B$ ), but the increases in $T_{s / c}$ and NK cells were smaller than in the control subjects. Accordingly, in both groups of patients the ratio $T_{h} / T_{s / c}$ cells was lower after exercise (control subjects: $0.8 \pm 0.2$ vs. $1.2 \pm 0.1, P=0.0125$; CHF patients: $1.8 \pm 0.4$ vs. $2.4 \pm 0.4, P=0.0161)$.

Leukocyte subsets after terbutaline treatment. In order to investigate whether prolonged exposure to adrenergic agonists (as observed in the heart failure patients) might have a different effect on lymphocyte subsets than acute increases (as observed with exercise), we treated healthy volunteers for $7 \mathrm{~d}$ with the $\beta$-adrenergic agonist terbutaline. This treatment decreased the white blood cell count and the number of circulating lymphocytes in 11 of 12 volunteers (Table IV). Looking at lymphocyte subsets, the number of NK and T cells decreased, whereas the number of $B$ cells did not change. The number of circulating NK cells was reduced in 8-10 of 11 volunteers (depending on which antibody was used to define these cells), and the average decrease among all subjects was $35-48 \%$. The reduction in the number of pan $T$ cells (10 of 11 volunteers) was predominantly due to a decrease in $T_{s / c}$-cell number ( 10 of 11 volunteers) with only a small decrease in $T_{h}$ cells. Accordingly, the $T_{h} / T_{s / c}$-cell ratio increased in 7 of 10 volunteers (Fig. 4).

\section{Discussion}

Growing evidence suggests that the responsiveness of the immune system is at least partly under the control of the sympathetic nervous system. The spleen and other lymphoid tissues are densely innervated with sympathetic nerve fibers (5), and lymphocytes have $\beta_{2}$-adrenergic receptors that couple to stimulation of adenylate cyclase (10). Numerous in vitro studies have shown that treatment of human lymphocytes with the $\beta$-adrenergic agonist isoproterenol (and other agents that elevate intracellular cAMP concentrations) reduces mitogen-induced increases in intracellular inositol-(1,4,5)-trisphosphate and calcium, production of IL-2 and IFN, expression of IL-2 receptors, immune cytolysis, antibody production, and plaque formation on sheep red blood cells, as well as IL-1 production by monocytes (for review, 11-13).

In vivo, an inhibitory effect of adrenergic agonists on lymphocyte proliferation has not yet been demonstrated directly. In animals, conditions of prolonged sympathetic overactivity like chronic stress suppress immunity (14-17). Similarly, the immune status can be altered in patients with CHF who also have an increased sympathetic activity $(18,19)$. We now extend these observations by demonstrating that patients with CHF have reduced numbers of circulating $T_{s / c}$ and NK cells but not $T_{h}$ and total white blood cells. Our data show that this alteration is not linked to the etiology of heart failure but rather correlated with the clinical severity of the disease. The elevation of plasma catecholamine levels in CHF patients is also linked to severity of disease, and plasma norepinephrine levels have previously been used as prognostic indicators in such patients (20). As patients with CHF can have numerous other hormonal alterations such as increased cortisol and angiotensin levels, we designed additional experiments to deter- 
Table III. Circulating Leukocytes and Plasma Catecholamines before and after Dynamic Exercise

\begin{tabular}{|c|c|c|c|c|c|c|}
\hline & \multicolumn{3}{|c|}{ Control subjects } & \multicolumn{3}{|c|}{ Heart failure patients } \\
\hline & Before* & After: & Increase & Before* & After ${ }^{*}$ & Increase $^{t}$ \\
\hline White blood cells & $6483 \pm 414$ & $9617 \pm 587^{\S}$ & $3133 \pm 276$ & $6713 \pm 835$ & $8188 \pm 1011^{\prime \prime}$ & $1475 \pm 349^{\prime \prime}$ \\
\hline Lymphocytes & $1818 \pm 116$ & $3304 \pm 234^{\S}$ & $1486 \pm 146$ & $1577 \pm 183$ & $2258 \pm 292^{\prime}$ & $681 \pm 150^{\top}$ \\
\hline \% Lymphocytes & $29.4 \pm 2.2$ & $36.1 \pm 2.5^{8}$ & $6.7 \pm 0.7$ & $25.1 \pm 2.7$ & $29.0 \pm 3.3^{* *}$ & $3.9 \pm 1.0^{\ddagger \ddagger}$ \\
\hline Norepinephrine & $395 \pm 69$ & $1475 \pm 303^{\prime \prime}$ & $1080 \pm 262$ & $469 \pm 74$ & $1110 \pm 150^{\S}$ & $641 \pm 95^{* *}$ \\
\hline Epinephrine & $91 \pm 14$ & $164 \pm 37^{\ddagger}$ & $72 \pm 32$ & $58 \pm 13$ & $101 \pm 24^{\ddagger \ddagger}$ & $43 \pm 16$ \\
\hline Dopamine & $452 \pm 106$ & $500 \pm 115$ & $48 \pm 93$ & $352 \pm 97$ & $419 \pm 132$ & $67 \pm 93$ \\
\hline
\end{tabular}

All numbers are mean \pm SEM of 16 control subjects and 14 heart failure patients. Cell numbers are given cells/ $\mu$, and plasma catecholamine concentrations in $\mathrm{pg} / \mathrm{ml}$. Significance of differences was calculated ${ }^{\ddagger}$ with paired two-tailed $t$ tests for the effect of exercise in each group, and * with unpaired two-tailed $t$ tests for the comparison of changes between control subjects and heart failure patients. ${ }^{\S} P<0.0001,{ }^{\prime} P<0.001$,

" $P<0.005,{ }^{* *} P<0.01,{ }^{\ddagger} P<0.05$ vs. pre-exercise values and vs. control subjects, respectively.

mine whether the heightened sympathetic activity is likely to be the cause of the alteration of circulating lymphocytes.

Previous studies have shown that acute stimulation of sympathetic activity by dynamic exercise or mental stress (21), as well as injections of epinephrine (22) increase the number of circulating lymphocytes with a predominant rise in $T_{s / c}, N K$, and $B$ cells, but only a modest change in $T_{h}$ cells. This lymphocytosis can be attributed to the adrenergic system, as it can be prevented by pretreatment with the $\beta$-adrenergic antagonist propranolol (23). As these changes are opposite to those we observed in heart failure patients with chronically heightened sympathetic activity, we repeated these experiments using a treadmill exercise protocol. Our data in control subjects and CHF patients confirm the previous reports of the other investigators. The underlying mechanism is not completely clear, but mediation via adrenergic receptors on the contractile elements and blood vessels of the spleen (5) appears to be likely. This idea is further supported by the recent observation that a 20 -min infusion of the $\beta$-adrenergic agonist isoproterenol in-
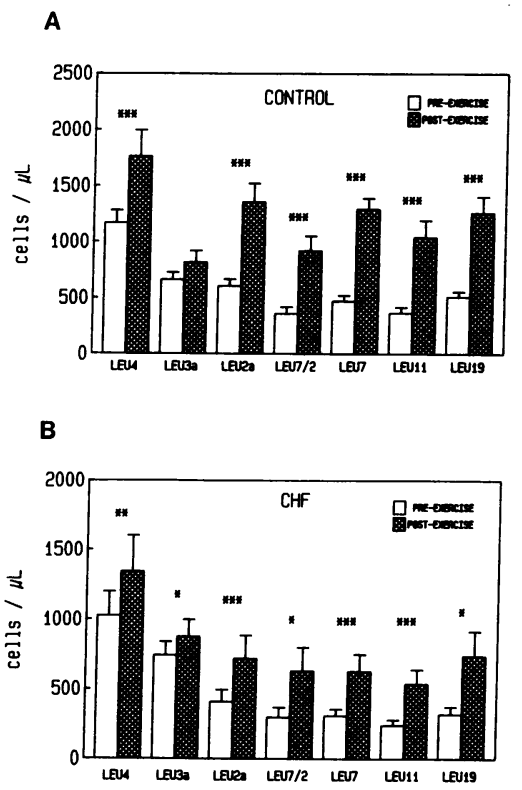

Figure 3. Effect of dynamic exercise on circulating lymphocyte subsets in control subjects ( $u p$ ) and heart failure patients (down). Shown are total $\mathrm{T}$ cells (Leu $4^{+}$), $T_{h}$ cells (Leu $\left.3 \mathrm{a}^{+}\right), \mathrm{T}_{\mathrm{s} / \mathrm{c}}$ cells (Leu $2 a^{+}$), the Leu $7 / 2^{+}$subset, and NK cells (Leu $7^{+}$, Leu $19^{+}$, and Leu $11^{+}$). Data are presented as means \pm SEM of the number of cells/ $\mu \mathrm{l}$ blood from 16 control subjects and 16 heart failure patients. ${ }^{*} P<0.05,{ }^{* *} P<0.001$ vs. pre-exercise values as assessed by paired two-tailed $t$ test. creases the number of circulating $T_{\mathrm{s} / \mathrm{c}}$ and NK cells in control subjects but not in splenectomized patients (24). The less pronounced increase in circulating lymphocytes in CHF patients could be explained by a lesser degree of exercise, a desensitization of the $\beta$-adrenergic receptors mediating this effect and/or by the possibility that the number of lymphocytes in the spleen is reduced in these patients.

In order to determine whether chronically elevated sympathetic activity might have different effects on circulating lymphocytes than acute stimulation, we tested the effect of prolonged treatment with a $\beta$-adrenergic agonist in healthy volunteers. To stimulate the lymphocyte $\beta_{2}$-adrenergic receptors, we chose the $\beta_{2}$-selective agonist terbutaline. Terbutaline treatment modestly decreased the number of circulating white blood cells. Whereas neutrophils, monocytes, and B cells were unaffected, and $T_{h}$ cells were only modestly reduced, the number of circulating $T_{\mathrm{s} / \mathrm{c}}$ and NK cells decreased markedly. These alterations mimic exactly those observed in the CHF patients. The plasma levels of epinephrine (nearly equipotent at both

Table IV. Effect of Terbutaline Treatment on the Number of Circulating Leukocytes

\begin{tabular}{lcccc}
\hline & Before & After & Decrease & $P$ value \\
\hline Total white blood cells & $6043 \pm 428$ & $5413 \pm 376$ & $629 \pm 154$ & 0.0022 \\
Neutrophils & $3540 \pm 226$ & $3251 \pm 268$ & $289 \pm 222$ & 0.2296 \\
Monocytes & $425 \pm 50$ & $392 \pm 43$ & $33 \pm 44$ & 0.4771 \\
Lymphocytes & $2269 \pm 213$ & $1868 \pm 177$ & $401 \pm 133$ & 0.0129 \\
B cells (CD19) & $141 \pm 22$ & $174 \pm 25$ & $-33 \pm 20$ & 0.1351 \\
T cells (CD3) & $1613 \pm 178$ & $1183 \pm 112$ & $429 \pm 101$ & 0.0017 \\
$\mathrm{~T}_{\mathrm{h}}$ cells (CD4) & $828 \pm 121$ & $706 \pm 77$ & $122 \pm 66$ & 0.0990 \\
$\mathrm{~T}_{\text {s/c }}$ cells (CD8) & $710 \pm 70$ & $466 \pm 39$ & $244 \pm 56$ & 0.0014 \\
Leu 7/2 subset & $190 \pm 28$ & $104 \pm 17$ & $87 \pm 19$ & 0.0009 \\
NK cells (Leu7) & $308 \pm 48$ & $207 \pm 35$ & $100 \pm 32$ & 0.0107 \\
NK cells (Leu11) & $311 \pm 37$ & $203 \pm 43$ & $108 \pm 36$ & 0.0160 \\
NK cells (Leu19) & $484 \pm 63$ & $264 \pm 43$ & $220 \pm 71$ & 0.0114
\end{tabular}

All numbers are mean \pm SEM of $10-12$ subjects, expressed as cells $/ \mu \mathrm{l}$. $P$ values were calculated by paired two-tailed $t$ test. 


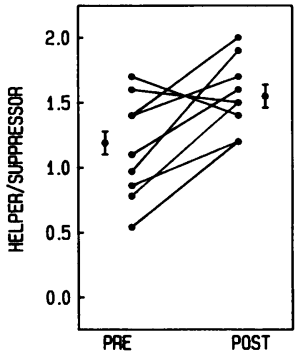

Figure 4. Effect of terbutaline treatment on the ratio of $T_{h} / T_{s / c}$ cells. The $T_{h} / T_{s / c^{-}}$ cell ratio was calculated for each individual from the data presented in Table IV. Shown are the individual data for all participating volunteers.

$\beta$-receptor subtypes) were not elevated in our patients, and the plasma levels of norepinephrine [selective for $\beta_{1}$ - vs. $\beta_{2}$-receptors (25)], are insufficient to effectively stimulate $\beta_{2}$-adrenergic receptors. At higher concentrations, however, norepinephrine is a full agonist at $\beta_{2}$-receptors. Such high concentrations of norepinephrine can exist locally in the lymphoid tissues (e.g., the spleen) where sympathetic nerve endings form junctions with lymphocytes that are even tighter than those in a synapse (5). Therefore, we consider it to be most likely that elevated sympathetic activity (via $\beta$-adrenergic receptors) causes the alterations of circulating lymphocyte subsets in CHF patients.

Our data do not explain why the number of circulating cells is decreased in only certain lymphocyte subsets. One possible explanation involves the different number and responsiveness of $\beta$-adrenergic receptors in lymphocyte subsets. $T_{h}$ cells, which were only modestly decreased after terbutaline treatment, have substantially less $\beta$-adrenergic receptors and generate less cAMP in response to the $\beta$-agonist isoproterenol than do NK and $\mathrm{T}_{\mathrm{s} / \mathrm{c}}$ cells (26). B cells have many $\beta$-adrenergic receptors but generate only little cAMP in response to isoproterenol, and their number was also not decreased after terbutaline treatment. These data thus indicate that $\beta$-adrenergic agonists decrease only those subsets of circulating lymphocytes that generate large amounts of CAMP in response to $\beta$-adrenergic receptor stimulation.

In summary, we have demonstrated that patients with CHF have a reduced number of circulating lymphocytes with a decrease in NK and $T_{s / c}$ cells but no change in $T_{h}$ cells. This alteration can be reproduced by treatment of healthy volunteers with the $\beta$-adrenergic agonist terbutaline. It is likely that these lymphocyte alterations are an epiphenomenon of heart failure. We propose that established lymphocyte alterations might be involved in the further pathophysiology of $\mathrm{CHF}$ and other diseases such as hypertension and chronic renal failure which are associated with chronically heightened sympathetic activity.

\section{Acknowledgments}

This work was supported by grants from the Veterans Administration, the National Institutes of Health, and the American Heart Association (California affiliate). Dr. Maisel is a Clinical Investigator of the National Institutes of Health, Dr. Motulsky is an Established Investigator of the American Heart Association, and Dr. Michel is a recipient of a fellowship of the Deutsche Forschungsgemeinschaft.

\section{References}

1. Packer, M. 1988. Neurohormonal interactions and adaptations in congestive heart failure. Circulation. 77:721-730.

2. Weber, M. A., and J. I. M. Drayer. 1982. The sympathetic nervous system in primary hypertension. Miner. Electrolyte Metab. 7:57-66.

3. Daul, A. E., X. L. Wang, M. C. Michel, and O.-E. Brodde. 1987. Arterial hypotension in chronic hemodialyzed patients. Kidney Int. 32:728-735.

4. Snavely, M. D., H. J. Motulsky, D. T. O’Connor, M. G. Ziegler, and P. A. Insel. 1982. Adrenergic receptors in human and experimental pheochromocytoma. Clin. Exp. Hypertens. 4:829-848.

5. Felten, D. L., S. Y. Felten, D. L. Bellinger, S. L. Carlson, K. D. Ackerman, K. S. Madden, J. A. Olschowki, and S. Livnat. 1987. Noradrenergic sympathetic neural interactions with the immune system: structure and function. Immunol. Rev. 100:225-260.

6. DeBlasi, A., A. S. Maisel, R. D. Feldman, M. G. Ziegler, M. Fratelli, M. DiLallo, D. A. Smith, C.-Y. C. Lai, and H. J. Motulsky. 1986. In vivo regulation of $\beta$-adrenergic receptors on human mononuclear leukocytes: assessment of receptor number, location, and function after posture change, exercise, and isoproterenol infusion. J. Clin. Endocrinol. \& Metab. 63:847-853.

7. Maisel, A. S., and H. J. Motulsky. 1987. Receptor distribution does not accompany terbutaline-induced down regulation of betaadrenergic receptors on human mononuclear leukocytes. Clin. Pharmacol. Ther. 42:100-106.

8. Durrett, L. R., and M. G. Ziegler. 1978. A sensitive radioenzymatic assay for catechol drugs. J. Neurosci. Res. 5:191-194.

9. Phillips, J. H., and L. L. Lanier. 1986. Lectin-dependent and anti-CD3 induced cytotoxicity are preferentially mediated by peripheral blood cytotoxic T lymphocytes expressing Leu 7 antigen. J. Immunol. 135:1579-1585.

10. Brodde, O.-E., G. Engel, D. Hoyer, K. D. Bock, and F. Weber 1981. The beta-adrenergic receptor in human lymphocytes-subclassification by the use of a new radio-ligand $\left.{ }^{(25} \mathrm{I}\right)$-Iodocyanopindolol. Life Sci. 29:2189-2198.

11. Bourne, H. R., L. M. Lichtenstein, K. L. Melmon, C. S. Henney, Y. Weinstein, and G. M. Shearer. 1974. Modulation of inflammation and immunity by cAMP: receptors for vasoactive hormones and mediators of inflammation regulate many leukocyte functions. Science (Wash. DC). 184:19-28.

12. Feldman, R. D., G. W. Hunninghake, and W. L. McArdle. 1987. $\beta$-Adrenergic receptor-mediated suppression of interleukin 2 receptors in human lymphocytes. J. Immunol. 139:3355-3359.

13. Kammer, G. M. 1988. The adenylate cyclase-cAMP-protein kinase A pathway and regulation of immune response. Immunol. Today. 9:222-229.

14. Monjan, A. A., and M. I. Collector. 1977. Stress-induced modulation of the immune response. Science (Wash. DC). 196:307-308.

15. Keller, S. E., J. M. Weiss, S. J. Schleifer, N. E. Miller, and M. Stein. 1981. Suppression of immunity by stress: effect of a graded series of stressors on lymphocyte stimulation in the rat. Science (Wash. DC). 213:1397-1400.

16. Keller, S. E., J. M. Weiss, S. J. Schleifer, N. E. Miller, and M. Stein. 1983. Stress-induced suppression of immunity in adrenalectomized rats. Science (Wash. DC). 221:1301-1304.

17. Laudenslager, M. L., S. M. Ryan, R. C. Drugan, R. L. Hyson, and S. F. Maier. 1983. Coping and immunosuppression: inescapable but not escapable shock suppresses lymphocyte proliferation. Science (Wash. DC). 221:568-570.

18. Anderson, J. L., J. F. Cardiquist, and E. H. Hammond. 1982. Deficient natural killer cell activity in patients with idiopathic dilated cardiomyopathy. Lancet. ii:1124-1127. 
19. Eckstein, R., W. Mempel, and H. D. Bolte. 1982. Reduced suppressor cell activity in congestive cardiomyopathy and in myocarditis. Circulation. 65:1224-1229.

20. Cohn, J. N., and T. S. Rector. 1988. Prognosis of congestive heart failure and predictors of mortality. Am. J. Cardiol. 62(Suppl. 2):25A-30A.

21. Landmann, R. M. A., F. B. Müller, C. Perini, M. Wesp, P. Erne, and F. R. Bühler. 1984. Changes of immunoregulatory cells induced by psychological and physical stress: relationship to plasma catecholamines. Clin. Exp. Immunol. 58:127-135.

22. Crary, B., S. L. Hauser, M. Borysenko, I. Kutz, C. Hoban, K. A. Ault, H. L. Weiner, and H. Benson. 1983. Epinephrine-induced changes in the distribution of lymphocyte subsets in peripheral blood of humans. J. Immunol. 131:1178-1181.

23. Ahlborg, B., and G. Ahlborg. 1970. Exercise leukocytosis with and without beta-adrenergic blockade. Acta Med. Scand. 187:241246 .

24. van Tits, L. J. H., M. C. Michel, H. Grosse-Wilde, M. Happel, F.-W. Eigler, A. Soleman, and O.-E. Brodde. 1990. Catecholamine-induced changes in lymphocyte $\beta_{2}$-adrenergic receptor number and proliferative response towards mitogens: a $\beta_{2}$-adrenergic, spleen-dependent process. Am. J. Physiol. In press.

25. Lands, A. M., A. Arnold, J. P. McAuliff, F. P. Luduena, and T. G. Brown. 1967. Differentiation of receptor systems activated by sympathetic amines. Nature (Lond.). 214:597-598.

26. Maisel, A. S., P. Fowler, A. Rearden, H. J. Motulsky, and M. C. Michel. 1989. A new method for isolation of human lymphocyte subsets reveals differential regulation of $\beta$-adrenergic receptors by terbutaline treatment. Clin. Pharmacol. Ther. 46:429-439. 